\title{
Going the Distance for International Students: Academic Integrity Support Online
}

Mandi Goodsett

Cleveland State University, a.goodsett@csuohio.edu

Follow this and additional works at: https://engagedscholarship.csuohio.edu/msl_facpub

Part of the Library and Information Science Commons

How does access to this work benefit you? Let us know!

\section{Publisher's Statement}

Copyright Taylor \& Francis. Final paper published in the Journal of Library \& Information

Services in Distance Learning: https://www.tandfonline.com/doi/abs/10.1080/

1533290X.2021.1896624?journalCode=wlis20

\section{Original Citation}

Goodsett, M. (2021). Going the Distance for International Students: Academic Integrity Support Online. Journal of Library \& Information Services in Distance Learning, 14(3-4): 209-227. https://doi.org/10.1080/ 1533290X.2021.1896624

\section{Repository Citation}

Goodsett, Mandi, "Going the Distance for International Students: Academic Integrity Support Online" (2021). Michael Schwartz Library Publications. 179.

https://engagedscholarship.csuohio.edu/msl_facpub/179

This Article is brought to you for free and open access by the Michael Schwartz Library at EngagedScholarship@CSU. It has been accepted for inclusion in Michael Schwartz Library Publications by an authorized administrator of EngagedScholarship@CSU. For more information, please contact library.es@csuohio.edu. 
Going the Distance for International Students: Academic Integrity Support Online

Mandi Goodsett 


\title{
Going the Distance for International Students: Academic Integrity Support Online
}

\author{
Mandi Goodsett
}

Performing Arts \& Humanities Librarian, OER \& Copyright Advisor, Cleveland State University, Cleveland, $\mathrm{OH}$, USA

\section{Introduction}

The COVID-19 pandemic has shed new light on the challenges for college students attending classes from a distance. As students attempt to engage with course content online, they may struggle to access the needed technology or connect with their instructor and peers (Karkar-Esperat, 2018). International students may feel even more disconnected from their campus due to language and cultural barriers. For this reason, targeted, online support is a valuable way to help international students succeed. A particular issue that online learning objects can help address is academic integrity, which is a concept that can be especially tricky for international students who come from a variety of cultural backgrounds with varying attitudes about academic sourcing.

The librarians at Cleveland State University (CSU) have been offering an online "avoiding plagiarism" workshop for students since 2015, and, most semesters, several hundred students enroll in the workshop to receive extra credit. The workshop consists of Blackboard modules that, if finished, result in a certificate of completion. When the director of the Center for International Services \& Programs at CSU learned about this popular online workshop, he reached out to the library to see if the workshop could 
be modified and offered to all incoming international students as a part of their campus orientation. This article describes how the library responded to this institutional need in a way that streamlined the work while still considering how to successfully teach international students these important concepts. Changes to the workshop were made based on a careful exploration of the literature on teaching international students; feedback from participant interviews also helped the librarians update the content for a successful student experience.

The research questions explored in this study are:

- What preferences do international students have regarding the use of online information literacy learning objects?

- What elements of online information literacy learning objects assist or impede the learning experiences of international students?

- How can an online workshop be designed using free or low-cost tools to help distance students - especially international students - learn information literacy concepts?

\section{Literature review}

\section{Academic barriers for international students}

Studies have shown that international students in higher education face significant challenges, including those presented by differences in culture, language, and academic customs (Liu et al., 2010). Culture is generally considered to include the music, food, clothing, holidays, etc. of a group of people, but it involves much more subtle elements as well, such as values, beliefs, and norms (Shapiro et al., 2014). International students encountering U.S. culture for the first time might experience "culture shock," which occurs when a traveler encounters many unfamiliar and overwhelming new cultural experiences when in a new place (Zhou et al., 2008). Some cultural differences which have proven to contribute to culture shock include Western individualism (as opposed to collectivism), Western informality (as opposed to egalitarianism), and the Western emphasis on efficiency and directness (as opposed to gradual communication) (Shapiro et al., 2014).

Closely tied to issues of culture are barriers of language for international students. Studies show that if learners attempt to master a new language after puberty, they may never achieve the mastery of a native speaker (Birdsong, 1999). The anxiety and low self-confidence second-languagelearners often feel can make the situation worse (Yashima et al., 2004). Because academic language is challenging enough for native speakers to understand, international students may initially understand as little as $10 \%$ of what they hear in the classroom (Ryan, 2005). The ability (or inability) 
to communicate has a significant impact on an international student's capacity to succeed academically.

International students may also experience a phenomenon called "academic shock," which results when the academic expectations and norms of their host country are new and confusing (Ryan, 2005). For international students visiting the United States, new academic expectations can include a difference in the formality of faculty-student relationships, an increase in the independence expected of students, or an unfamiliarity with methods of class discussion (Ryan, 2005). The academic systems in the home countries of international students may differ from those in the U.S.; they may be more rigid and discourage discussion, and the instructor may be considered an authority who should not be challenged (Badke, 2002; Koenigstein, 2012; Ganster, 2011).

Many aspects of the international experience may cause international students to experience greater stress and anxiety, including changes in the immigration security measures facing those trying to enter the U.S. (Jackson, 2005). All of these impairments should encourage instruction meant for international students to provide more time, leeway, and accommodations for international students wherever possible.

\section{Academic integrity and international students}

Plagiarism has become an especially difficult problem for higher education institutions because of the technology available for students to find creative ways to avoid creating original content in writing assignments (Velliaris \& Breen, 2016). Copy-and-paste plagiarism, which occurs when students take word-for-word portions of several sources and combine them (Velliaris \& Breen, 2016), is made easier by the latest technology (Abdul-Ameer \& Hussein, 2015). Students may commit plagiarism for a variety of reasons, however, including differing cultural backgrounds regarding its appropriateness, peer pressure, lack of time management skills, or stress (Keenan \& Jemmeson, 2004; University of Alberta, 2001).

For international students, there exist unique challenges related to academic integrity. For example, in many non-Western cultures, educational models prioritize memorizing facts over analysis. Learning may be seen as comprehending a nation's vast knowledge-base developed over time, and not necessarily involve producing new knowledge (Badke, 2002). Therefore, research and writing in non-Western cultures often means synthesizing ideas that are already known, not developing new ones or disputing existing ideas about controversial subjects (Badke, 2002). In collectivist cultures (for example, in China), information is thought to belong to the collective rather than individuals, which makes American conceptions of citation and 
plagiarism more difficult to grasp (Koenigstein, 2012; Hughes, 2005). In these cultures, deviating from the words of a respected author may seem egotistical or over-confident (Juwah et al., 2008). Alternatively, in the Arab world, memorizing and repeating traditional songs and stories is an important cultural tradition that international students may find difficult to square with Western academic practices of analysis and original composition (Fawley, 2012).

Another problem is that international students from a variety of regions may come from countries that do not consider plagiarism to be a "big issue" worthy of severe punishment; as the thinking goes, the significant amount of work needed to piece together word-for-word texts in plagiarized writing should perhaps be rewarded (Sarkodie-Mensah, 2010). For example, a study in Pakistan found that more than half of the undergraduate and graduate students surveyed had engaged in activities that would be considered academic dishonesty in the United States, and there was no institutional punishment for this behavior (Nazir \& Aslam, 2010).

International students may experience additional academic integrity challenges due to a lack of proficiency in English (Hyland, 2001; Park, 2003). When reading comprehension and writing tasks are already challenging, properly organizing and citing sources may be a low priority or especially onerous. There can be a temptation to use the "beautiful sentences" from outside sources, when composing and translating them from their native language is so laborious (Bista, 2011). Citing sources correctly and consistently also requires good study skills, such as note-taking skills, which international students may not have adequately developed (Bista, 2011). International students may be experiencing significant psychological pressure and issues related to adjusting to a new environment, e.g. homesickness, a sense of isolation, and anxiety (Bista, 2011). These issues leave international students at a disadvantage in developing their study skills and producing original writing with confidence.

Academic pressures that all students - international and domestic encounter, such as peer pressure and a desire to save time, may lead to plagiarism as well (Bista, 2011). For these reasons, concepts of academic integrity can be especially difficult to learn for international students visiting the United States.

\section{Teaching international students online}

The increasing demand for online delivery of instruction is considerably altering higher education. Even while offerings of distance learning have grown in recent years, the COVID-19 pandemic caused the demand for 
online learning materials to skyrocket (UNESCO, 2020). The challenge of transitioning content to an online format is to maintain a high level of instructional quality in the online environment. Fortunately, when providing research support to international students, online learning can meet inperson instruction's quality; in fact, it can meet the needs of international students in ways that are more difficult in-person.

Online learning can be much more self-paced, allowing students to take the necessary time to craft interactions and complete assignments (Murphy et al., 2002; Perumalla et al., 2011). This can be especially helpful for international students, who sometimes must overcome language barriers and work harder than domestic students to understand the content itself. Asynchronous, online course materials allow international students to slow down video content, view video content with subtitles, use a translator for textual content, consult the campus writing center as necessary, and write assignments in their native language and then translate, if needed (Ison \& Didia, 2020; Karkar-Esperat, 2018). If international students are completing the work in a different time zone, asynchronous, online content also allows them to learn at a time that is convenient for them.

Johnson and Aragon (2003) present a framework for teaching in online learning environments that employs the following principles: encourage social interaction, avoid information overload, provide hands-on activities, address individual differences, encourage student reflection, create a reallife context, and motivate the student (Johnson \& Aragon, 2003). These principles can be encouraged by employing multiple formats of content, using engaging games, "chunking" material, using simulations or case studies, establishing a personal connection with students, encouraging reflection, and applying active learning exercises. This framework was employed, along with a review of relevant literature, to design the anti-plagiarism online workshop described in the present study.

While there are affordances of online learning for international students, there are also challenges related to cultural and language barriers (Liu et al., 2010). Online learning content developed for international students should be designed to avoid these challenges for its intended audience. For example, librarians should steer clear of long blocks of text, and content should be offered in multiple formats (Hodge, 2019). Library or other academic jargon should be avoided, as well as idioms and American cultural references (Hutcherson, 2004). If library jargon is used, clear definitions should be provided. Asynchronous learning modules should be considered, as they allow international students to feel a sense of control over their learning, which reduces anxiety (Karkar-Esperat, 2018). Thorough instructions and opportunities for getting help should also be easily accessible at the point of need (Karkar-Esperat, 2018). 


\section{Background}

Cleveland State University (CSU) is a doctoral-granting public university located in downtown Cleveland. Student enrollment is approximately 17,000 students, about $7 \%(1,280)$ of which are international. The ratio of graduate-to-undergraduate international students at CSU is roughly 4:5. CSU international students are supported by the Center for International Services and Programs (CISP).

In the spring of 2015, the Michael Schwartz Library, CSU's main library, decided to offer several in-person workshops as part of a Learn It@ the Library workshop series. Workshop topics included PowerPoint how-tos, navigating e-book collections, and avoiding plagiarism. While the workshops were well-advertised and attendees were entered into a drawing to win a library goody bag, attendance was very low (between two and five per session, with most attendees consisting of library staff).

In the fall of 2015, the library decided to transition some of the workshops online. It was thought that this would allow students to participate virtually and provide the library with more robust assessment data, including an opportunity to evaluate student understanding of the concepts covered. Because it was the highest attended among the in-person workshops offered, the Avoiding Plagiarism workshop was the first to be moved online.

The CSU learning management system, Blackboard, was the platform selected for the online workshop. The workshop was titled "Don't Be a Copycat: Avoiding Plagiarism," and featured a cat theme to make the content more approachable and fun. The author of the present study, with help from a Kent State University iSchool practicum student, developed four Blackboard modules: 1) What is plagiarism?; 2) Why should I cite my sources?; 3) How can I integrate my sources?; and 4) How can I cite a source in MLA or APA style? Each module consisted of a short video (replete with cat puns) recorded in PowerPoint and supplemented with H5P questions in a later semester (H5P, n.d.), as well as a short activity to be submitted for grading. (See Appendix B for screenshots of each module in Blackboard.) None of the activities could be graded automatically; the librarian needed to examine each submission and provide individual feedback. While more time-consuming, this method of assessment was chosen because it was found to be a more authentic and robust method of checking students' understanding of the concepts. The workshop also required students to complete an identical pre- and post-test to assess the workshop's success. (Much of the workshop content can be found in this research guide: https://researchguides.csuohio.edu/plagiarism101.)

The new workshop was marketed primarily to first-year writing and first-year experience instructors. In the first semester, 50 students enrolled 
in the online workshop and 39 of them completed it (as compared to thirteen students for the in-person workshops the previous semester). As faculty became aware of the workshop, the enrollment grew significantly. Average enrollment each semester was 187 students, with the most enrolled in one semester (410) in the fall of 2016, and the fewest (12) in the spring of 2016. An average of 58 students completed the workshop each semester. Many of the students were enrolled as part of a first-year writing course, but others were enrolled as part of upper-level courses in science and social science fields. Faculty who were especially concerned by existing levels of plagiarism made the workshop a required component of their course and gave participants a grade for completing it.

In 2018, CSU's Code of Student Conduct was reevaluated and updated by a small committee, of which the author of the present study was a member. The director of the Center for International Services and Programs (CISP) at the time was also a member of this committee, and over the course of the committee's meetings, he came to learn about the library's online workshop. He approached the library about requiring every incoming international student to complete the workshop. Because of the workload involved, the author asked for additional help from CISP to grade the workshop activities. Sean Siswanto, a graduate assistant working for CISP, took on these additional responsibilities. In the summer of 2020, Cruz Moreno, an undergraduate student employee for the Michael Schwartz Library, also contributed to the project.

Starting in the fall of 2019, all international students were automatically enrolled in the Blackboard course containing the workshop. They were informed about the workshop in the international student orientation and through Blackboard announcements. The workshop team set a deadline for completion, and international students who did not complete the workshop by that date would not be able to register for classes the following semester until the workshop was completed.

The workshop in the fall of 2019 saw 414 students enroll, and 168 completed the required assignments. Some changes were made to the workshop after the first iteration, based on feedback from Sean, including streamlining the assignment submission process, simplifying the text of examples, and reducing the workload of some assignments. The workshop was offered again in the summer and fall semesters of 2020; however, only students enrolled in the fall 2019/spring 2020 iteration were interviewed for this study.

\section{Methods}

The original audience of the Avoiding Plagiarism workshop was first-year domestic students with presumably some introduction to the U.S. conception 
of plagiarism from prior education. In an attempt to modify the workshop to better meet the needs of the international students, the author of the present study conducted a literature review and interviewed seven of the workshop participants for feedback. While surveys are typically used to obtain feedback and information from international students (Click et al., 2017), interviews were chosen for this project because of their potential to provide more indepth, nuanced answers to the stated research questions.

Participants in the interviews were CSU international students who had at least attempted all parts of the Avoiding Plagiarism workshop offered in the fall of 2019 and spring of 2020. Participants received a $\$ 10$ credit to their university account to be used for university-related purchases (such as at the campus bookstore). Initially, students were selected using a random number generator and solicited to participate in an interview. However, the response rate to this method was so low - possibly due to the COVID-19 pandemic - that the author instead reached out to all students who had completed the workshop to solicit interviews on a first-come, first-served basis. Seven students responded and participated in a 15-30 minute semistructured interview over Zoom. The interview questionnaire can be found in Appendix A. The participants spanned a range of educational levels and came from a variety of world regions. [Table 1 near here.]

Table 1. Study participant demographics.

\begin{tabular}{lllll}
\hline Pseudonym & Country of Origin & Educational Level & \multicolumn{1}{c}{ Field of Study } & Amount of Time in U.S. \\
\hline Student A & Iran & Graduate & Applied Biomedical Engineering & 1 year \\
Student B & Bangladesh & Undergraduate & Accounting & 1 year \\
Student C & India & Graduate & Mechanical Engineering & 9 months \\
Student D & India & Graduate & Mechanical Engineering & 9 months \\
Student E & Vietnam & Undergraduate & Marketing, International Business & 3.5 years \\
Student F & Saudi Arabia & Undergraduate & Nursing & 3 years \\
Student G & Pakistan & Graduate & Transportation Engineering & 8 months \\
\hline
\end{tabular}

The interviews were recorded and a transcript was generated by Zoom and corrected by the author. The author, with help from Sean and Cruz, used the transcripts to identify ideas and themes related to the study research questions. These preliminary codes were then grouped into categories, which were used to answer the study research questions. The student interview feedback, along with the literature review, helped the researcher identify several aspects of the online workshops that were especially useful for international students, and other elements that could be changed or added.

\section{Results}

The themes developed from reading the transcripts were grouped according to the initial research questions (see the Introduction). 


\section{Preferences}

Many of the interview subjects shared their preferences regarding how an anti-plagiarism workshop such as CSU's should be offered online. Two participants found the cat-themed videos cute and "pretty ... fun with the content and the videos," and liked the fact that the tone of the videos was light. One student found the videos to be too juvenile.

Most of the participants commented on the format of the workshop, and some suggested alternatives to an asynchronous, online format. Two believed that an in-person workshop would be more helpful and would allow for more successful learning, though one acknowledged that an in-person workshop would be especially difficult during the COVID-19 pandemic. Several students voiced support for a live (as opposed to the asynchronous) online format of the workshop. However, one admitted that, unless a live session was required, many students would not attend. Some students also pointed out that the asynchronous format allowed more flexibility, but that there was sometimes an attitude among students that they could "take it less seriously." How to choose the most effective format for the workshop remains a challenge, but, overall, measures to require participation in any format are clearly important.

\section{Impediments and assets}

The interview questions attempted to determine which elements of the online workshop helped students learn and which ones presented barriers. One challenge mentioned frequently was the citation activity in Module 4. In this activity, students were shown two sources and required to cite them correctly from scratch. Without scaffolding and support, this activity was very challenging for students. One student said: "I was really struggling with [citation]. It was out of my comfort zone, I would say." While many students demonstrated competence regarding an understanding of plagiarism and why it matters, a number of them were still uncomfortable with citation skills after completing the workshop.

One surprising asset that was not built into the workshop was the students' ability to work with friends. When asked if they sought help at any point in the workshop, three students replied in the affirmative but did not describe reaching out to the workshop facilitators or the library; instead, the students turned to their friends for help. Several participants even described the process of completing the workshop with one or more other international students. One framed this desire to work with friends as a cultural preference: "When you have like a lot of Indian students in one course... we tend to stick together and study." 


\section{Online learning design}

Many of the participants provided helpful feedback about the design of the workshop, or provided ideas for future design elements. While this workshop was initially designed for both domestic and international first-year students, nearly half of the international student population at [Institution] is composed of graduate students. One graduate student participant opined that the material in the workshop was insufficiently advanced and therefore inappropriate for a graduate student audience: "The content of what I was doing was not in a level that graduate students might like to see ... The content is not that much reach. It's so basic."

A number of students also referred to their desire to - or actual experience of returning to - the workshop content later as needed, e.g. for reference. One said: "If I was supposed to write down any research paper or literature survey today, I think I would need to refer back to that content." Another described frustration about trying to find relevant information in a workshop video, saying: "I was trying to refer back to that workshop, but I had to open the entire video again." Another student requested what he called a "journal," which seemed to mean a downloadable document or static website with workshop content that could be referred to later.

\section{Other themes}

Some themes that emerged while reading the participant transcripts did not fit well into the study's research questions, but still provided valuable insight. For example, several students expressed concern about deadlines for the workshop and felt that there was insufficient communication about them. One student described her experience asking other departments on campus about the workshop, such as her academic advisor and the Writing Center. These support services were able to help her, but they had limited information about the plagiarism workshop, as the facilitators had not reached out with details and contact information for questions.

One theme in the student responses had to do with student attitudes toward plagiarism and its consequences. Several participants said that their friends who were also taking the workshop did not "take it seriously," and expressed concern that the importance of the topic be emphasized to the international student community. Two participants implied that committing plagiarism is a crime, and many seemed worried about the punitive consequences of plagiarizing. While a primary objective of the workshop was to reduce occurrences of plagiarism among CSU international students, the goal was not to frighten the participants or give them the impression that accidental plagiarism is a criminal offense. A balance between 
emphasizing the seriousness of the topic, while also empowering students to avoid plagiarism with confidence - not fear - is necessary.

Student participants also described some of the cultural differences they experienced between their home countries and the United States regarding intellectual property and academic integrity. For example, one student said: "Culturally, it is something basic in Iran we memorize everything. And I reached here and ... when I first attend the schools, it was really shocking to me that nothing is memorized here. Everything is based on what we will learn. So yes ... I had this cultural shock." Another noted: "So back in Vietnam, plagiarism is seen as not as problematic as is seen in the United States. We can do it. Like I think when I was in high school, I think the teacher actually know that we actively take stuff from the prompt, take stuff from online and use that as our own work, and they say nothing about it... And when I got the United States I still have that mindset. Like, if I take stuff from download from the Internet, I change it a little bit like add some stuff in it. And, okay, maybe they won't notice. But no, it is a big problem, is very, very big problem." Yet another student noted: "I believe it's not a matter of not resisting of observing plagiarism [for international students], it's the matter of culture and the matter of English."

All of the participants were asked if they had learned anything from participating in the workshop, and all answered "yes" to this question. It was reassuring to learn that, despite the challenges that participants faced, many had found the workshop valuable and had learned from participating.

\section{Anticipated solutions}

Based on the themes that emerged in response to the study's research questions, the author of the present study plans to make several changes to the workshop going forward. To address the concerns about workshop format, the workshop team will offer several optional Zoom sessions for attendees to ask questions and receive explanations in real time. The workshop itself will remain asynchronous, however, to accommodate the schedules of international student participants.

Rather than preventing the participants from working with friends on the workshop, the organizers will add information directly addressing group work on workshop activities. Working with peers will be allowed, but providing identical answers will not. For students who desire a citation reference resource to consult after the workshop ends, the organizers will provide a short document for each module. The same content will be available on a research guide that can be updated as needed.

Workshop participants seem comfortable with the idea that plagiarism is a serious academic integrity infringement, but they confuse plagiarism with 
copyright violation. More content explaining the difference (and the different consequences each warrants) will be added to the workshop. While somewhat comfortable with why plagiarism is problematic after completing the workshop, participants still seem confused and anxious about citing sources. To address the difficulties students had in completing the citation activity, the workshop organizers will re-write the last module to allow for more scaffolding. For example, the students could be asked to fill in the blanks of a citation, put the pieces of a citation in order, or explore a specific citation resource, such as a citation research guide or the Purdue OWL website.

\section{Recommendations}

In the course of redesigning this anti-plagiarism workshop and conducting the qualitative research described, the author has developed several practical recommendations for other libraries hoping to improve their anti-plagiarism outreach to international students. Initiating conversations with international students and directly asking them for their perspectives was a very positive experience. Many international students in this study seemed eager to connect with a genuine listener. It was also valuable to the researchers to gain a sense of the distinctive international student population at this institution. Reach out to your international students via surveys, interviews, or focus groups to learn about their preferences and to build positive relationships.

If a library is developing anti-plagiarism workshop materials for international students from scratch, proceed with the target audience in mind. Does the international student population consist mostly of graduate or undergraduate students? Are most international students in one or two departments? Do many of your international students come from a single region? If so, what is the attitude toward intellectual property there? The international student population at any given institution is not a monolith and may have diverse needs.

Design the anti-plagiarism workshop carefully, balancing an emphasis on what plagiarism is and why citation is important, with scaffolded paraphrasing and citation exercises. While it can be challenging, help participants recognize the seriousness of plagiarism without instilling a sense of fear or dread. Recognize the cultural differences with which international students approach the subject of plagiarism. What may seem obvious to a native of the United States may be counterintuitive to a student from a different cultural background. Avoid addressing the subject of plagiarism with a paternalistic or ethnocentric attitude. While the students will need to understand the American approach to academic integrity, instruction should not present the American perspective as if it is inherently superior. 


\section{Conclusion}

International students may have special difficulty understanding and applying U.S. ideas about academic integrity, and libraries can play a role in teaching these important concepts. While more students than ever are experiencing classes online, online education for international students must be carefully planned and targeted to its intended audience. When well-designed, online, anti-plagiarism learning content has the potential to teach international students important academic integrity concepts while allowing for the increased flexibility and support needed to help them succeed.

\section{Disclosure statement}

No financial interest or benefit has arisen from the direct applications of this research.

\section{ORCID}

Mandi Goodsett (1) http://orcid.org/0000-0003-0477-2828

\section{References}

Abdul-Ameer, M. A., \& Hussein, K. S. (2015). Plagiarism and patchwriting detection in EFL students' graduation research writing. Al-Ma'mon College Journal, 26, 340-367.

Badke, W. (2002). International students: Information literacy or academic literacy. Academic Exchange Quarterly, 6(4), 60-65.

Birdsong, D. (Ed.). (1999). Second language acquisition and the critical period hypothesis. Routledge.

Bista, K. (2011). Academic dishonesty among international students in higher education. To Improve the Academy, 30(1), 159-171. https://doi.org/10.1002/j.2334-4822.2011. tb00655.x

Click, A. B., Walker Wiley, C., \& Houlihan, M. (2017). The internationalization of the academic library: A systematic review of 25 years of literature on international students. College \& Research Libraries, 78(3), 328. https://doi.org/10.5860/crl.78.3.328

Fawley, N. (2012). Addressing academic integrity: Perspectives from Virginia Commonwealth University in Qatar. In Jackson, P. \& Sullivan P. International Students and Academic Libraries: Initiatives for Success. (p 177). Association of College \& Research Libraries.

Ganster, L. (2011). Reaching out to international students: A focus-group approach to developing web resources and services. College \& Undergraduate Libraries, 18(4), 368-384. https://doi.org/10.1080/10691316.2011.624933

H5P. (n.d.) H5P: Create, share and reuse interactive HTML5 content in your browser. https://h5p.org/.

Hodge, M. (2019). Online learning through LibGuides for English language learners: A case study and best practices. In Tran, Y. \& Higgins, S. (Eds.), Supporting today's students in the library: Strategies for retaining and graduating international, transfer, first-generation, and re-entry students. (pp. 79-89). Association of College \& Research Libraries. 
Hughes, H. (2005). Actions and reactions: exploring international students' use of online information resources. Australian Academic \& Research Libraries, 36(4), 169-179. https://doi.org/10.1080/00048623.2005.10755308

Hutcherson, N. B. (2004). Library jargon: Student recognition of terms and concepts commonly used by librarians in the classroom. College \& Research Libraries, 65(4), 349-354. https://crl.acrl.org/index.php/crl/article/view/15676. https://doi.org/10.5860/crl.65.4.349

Hyland, F. (2001). Dealing with plagiarism when giving feedback. ELT Journal, 55(4), 375-381. https://doi.org/10.1093/elt/55.4.375

Ison, I., \& Didia, L. (2020). Lost and Found in Translation. Business Education Innovation Journal, 12(1), 186-189.

Jackson, P. A. (2005). Incoming international students and the library: a survey. Reference Services Review, 33(2), 197-209. https://doi.org/10.1108/00907320510597408

Johnson, S. D., \& Aragon, S. R. (2003). An instructional strategy framework for online learning environments. New Directions for Adult and Continuing Education, 2003(100), 31-43. https://doi.org/10.1002/ace.117

Juwah, C., Lal, D., \& Belouci, A. (2008). Overcoming the cultural issues associated with plagiarism for international students. The Plagiarism Project. The Robert Gordon University. http://informationliteracyatsenecalibraries.pbworks.com/f/RobertGordon_article.doc.

Karkar-Esperat, T. M. (2018). International graduate students' challenges and learning experiences in online classes. Journal of International Students, 8(4), 1722-1735. https:// doi.org/10.5281/zenodo.1468076

Keenan, C., \& Jemmeson, P. (2004). International students and plagiarism. A review of the literature. In Hall, B. (Ed.), Plagiarism among international students. (pp 1-10). PB Works. http://hazelsictenhancedlearningsite.pbworks.com/f/Plagiarism\%20and\% 20International\%20Students.pdf.

Koenigstein, D. (2012). Alleviating International Students' Culture Shock and Anxiety in American Academic Libraries: Welcome, Ahlan Wa Sahlan, Anyeong Hae Sae Yo, Bienvenidos, Huan Ying, Sanu Da Zuwa, Shalom, Swaagat Hai. Library Philosophy and Practice. https://digitalcommons.unl.edu/libphilprac/738/.

Liu, X., Liu, S., Seung-Hee, L., \& Magjuka, R. J. (2010). Cultural differences in online learning: International student perceptions. Journal of Educational Technology \& Society, 13(3), 177-188. https://www.jstor.org/stable/pdf/jeductechsoci.13.3.177.pdf.

Murphy, C., Hawkes, L., \& Law, J. (2002). How international students can benefit from a web-based college orientation. New Directions for Higher Education, 2002(117), 37-44. https://doi.org/10.1002/he.45

Nazir, M. S., \& Aslam, M. S. (2010). Academic dishonesty and perceptions of Pakistani students. International Journal of Educational Management, 24(7), 655-668. https://doi.org/ $10.1108 / 09513541011080020$

Park, C. (2003). In other words: Plagiarism by university students - literature and lessons. Assessment \& Evaluation in Higher Education, 28(5), 471-489. https://doi.org/10.1080/ 02602930301677

Perumalla, C., Mak, J., Kee, N., \& Matthews, S. (2011). Integrating web applications to provide an effective distance online learning environment for students. Procedia Computer Science, 3, 770-784. https://doi.org/10.1016/j.procs.2010.12.127

Ryan, J. (2005). The student experience. Teaching international students: Improving learning for all., 147-151. Taylor \& Francis.

Sarkodie-Mensah, K. (2010). Plagiarism and the international student. Catholic Library World, 80(3), 197-203. 
Shapiro, S., Farrelly, R., \& Tomaš, Z. (2014). Fostering international student success in higher education. TESOL International Association.

UNESCO. (2020). 290 million students out of school due-COVID-19: UNESCO releases first global numbers and mobilizes response. https://en.unesco.org/news/290-million-students-out-school-due-covid-19-unesco-releases-first-global-numbers-and-mobilizes.

University of Alberta. (2001). Why students plagiarize. University of Alberta Libraries. https://www.library.ualberta.ca/guides/plagiarism/why/index.cfm.

Velliaris, D. M., \& Breen, P. (2016). An institutional three-stage framework: Elevating academic writing and integrity standards of international pathway students. Journal of International Students, 6(2), 565-587. https://doi.org/10.32674/jis.v6i2.371

Yashima, T., Zenuk-Nishide, L., \& Shimizu, K. (2004). The influence of attitudes and affect on willingness to communicate and second language communication. Language Learning, 54(1), 119-152. https://doi.org/10.1111/j.1467-9922.2004.00250.x

Zhou, Y., Jindal-Snape, D., Topping, K., \& Todman, J. (2008). Theoretical models of culture shock and adaptation in international students in higher education. Studies in Higher Education, 33(1), 63-75. https://doi.org/10.1080/03075070701794833 


\section{Appendix A}

\section{Interview questionnaire}

Demographic Information

1. Could you please share your nationality and the amount of time you've spent in the United States?

2. What brought you to [institution]?

3. What are you studying?

4. In what year of your studies are you?

5. Have you been asked to complete a research assignment since starting as a student at [institution]? If yes, can you describe it?

6. If yes, did you complete it before, during, or after completing the Avoiding Plagiarism online workshop?

Online Workshop

1. How much of the Avoiding Plagiarism workshop did you finish?

2. About how long did it take you to finish? (Or to do the amount you completed?)

Access

1. How did you access the Avoiding Plagiarism workshop?

2. What challenges did you have finding the workshop and its modules, if any?

3. Did you seek help? If yes, how and what was your experience?

\section{Content}

1. To what extent did you understand plagiarism before completing the workshop?

2. How comfortable were you with the idea of plagiarism in the United States?

3. In module 1 of the workshop, you were asked to tell us whether the example student committed plagiarism. Did you find the content and activities of module 1 to be an appropriate difficulty level? Why/why not?

a. Any additional comments about this module?

4. In module 2 of the workshop, you were asked to read about a real student who committed plagiarism and summarize what happened. Did you find the content and activities of module 2 to be an appropriate difficulty level? Why/why not?

a. Any additional comments about this module?

5. In module 3 of the workshop, you were asked to read a short passage and paraphrase it. Did you find the content and activities of module 3 to be an appropriate difficulty level? Why/why not?

a. Any additional comments about this module?

6. In module 4 of the workshop, you were asked to cite a book and an article. Did you find the content and activities of module 4 to be an appropriate difficulty level? Why/why not?

a. Any additional comments about this module?

7. What challenges did you face completing the workshop requirements, if any?

a. Did you encounter any language/reading barriers? 
8. Did you feel more comfortable with plagiarism-related-concepts after taking the workshop? Why/why not?

9. If you completed a research project during or after completing the Avoiding Plagiarism workshop, did your participation in the workshop have any impact on your research process or the final research project?

10. How do you feel your participation will impact your future behaviors, if at all?

11. If you could change this Avoiding Plagiarism workshop for future students, what would you change?

12. Any additional thoughts or comments?

\section{Appendix B}

Screenshots of Plagiarism Workshop Modules

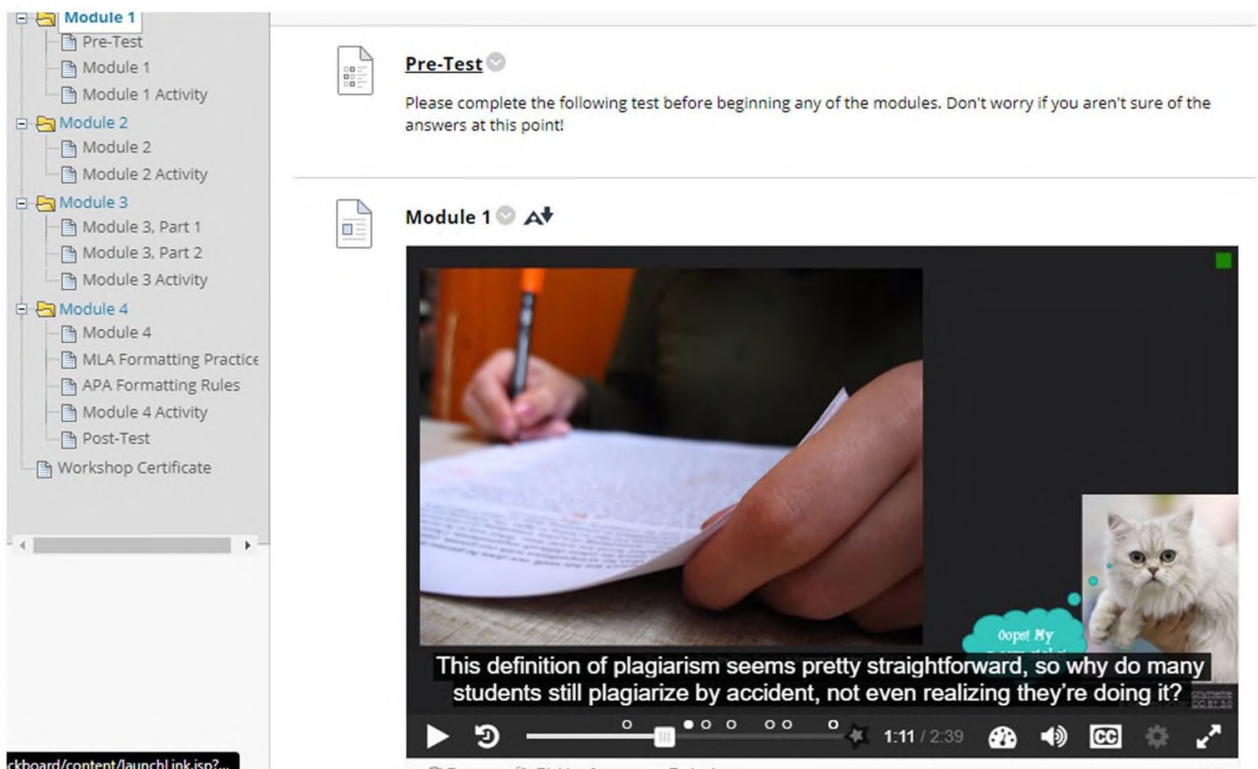

Module 1

Module 1 


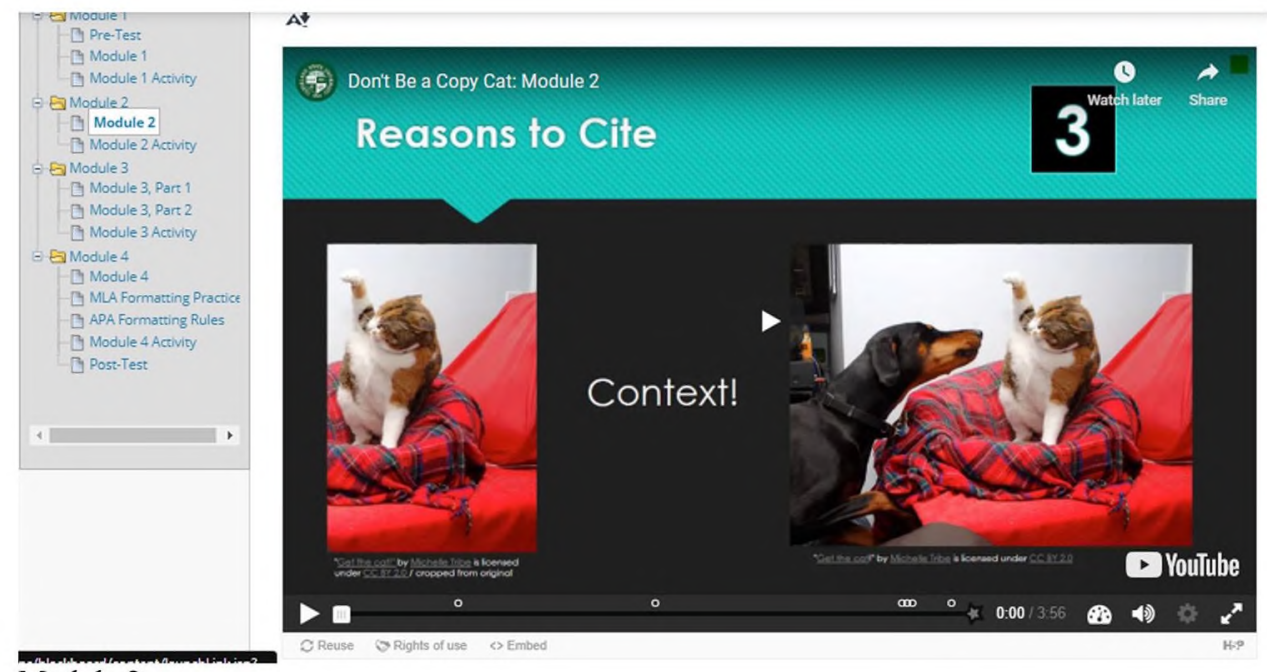

Module 2

Module 2
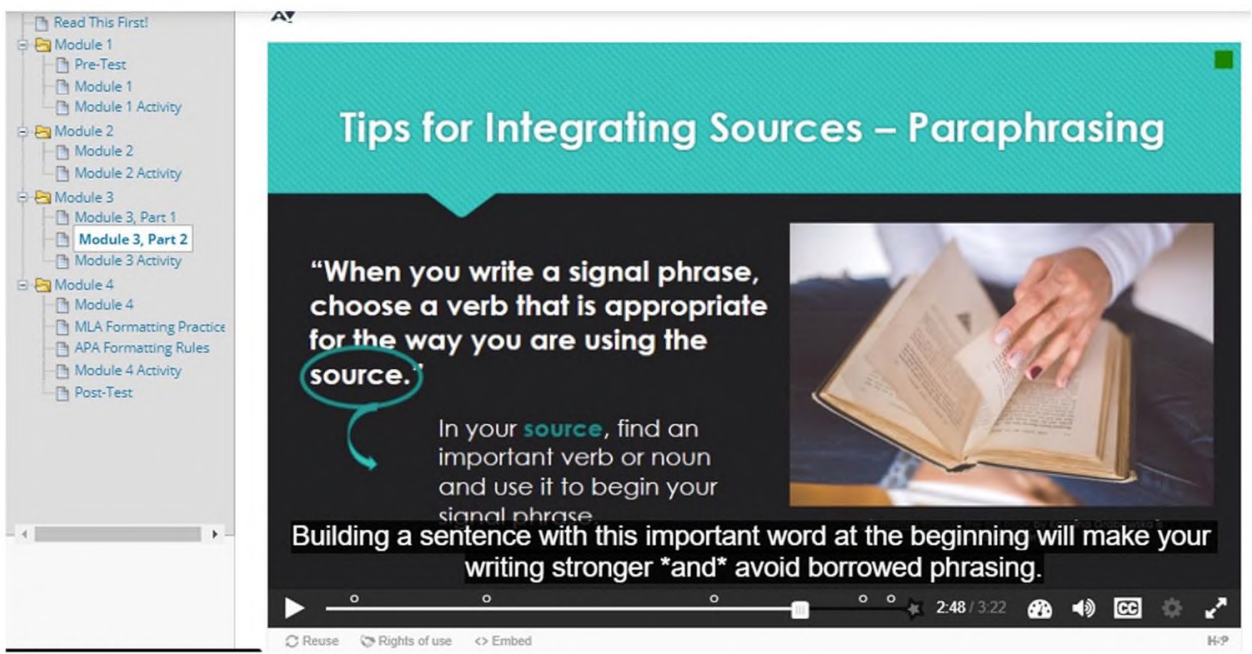

Module 3

Module 3 


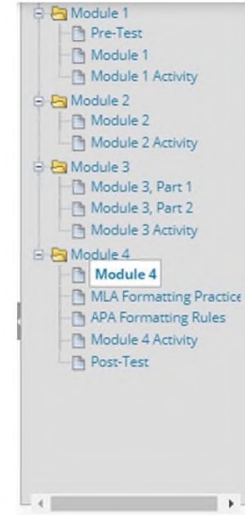

Module 4

Module 4

\section{We're here to help!}

O Reference Desk/Librarians

Writing Center

O Ask your Professor!

Finally, you may also want to ask your professor directly if you encounter a tricky citation situation.

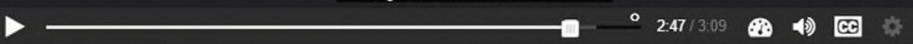

$\bigcirc$ Reuse $\checkmark$ Rights of use $\diamond$ Embed

$247 / 309$ (1) $x^{x}$ 